\title{
Block Design Subtest (WAIS-IV)
}

National Cancer Institute

\section{Source}

National Cancer Institute. Block Design Subtest (WAIS-IV). NCI Thesaurus. Code C120364.

A subtest of the Wechsler Adult Intelligence Scale, 4th Edition that measures spatial perception, visual abstract processing, and problem solving. 